\title{
Disponibilidade hídrica e distinção de ambientes para cultivo de cafeeiros
}

\author{
Milson E. Serafim', Geraldo C. de Oliveira², José M. de Lima², \\ Bruno M. Silva ${ }^{2}$, Walmes M. Zeviani ${ }^{3}$ \& Vico M. P. Lima ${ }^{4}$
}

\begin{abstract}
RESUMO
Este estudo foi realizado nos municípios de São Roque de Minas e Vargem Bonita, MG, com o objetivo de distinguir ambientes cultivados com cafeeiros quanto à disponibilidade hídrica para a cultura. A umidade de oito glebas de cafeeiro foi monitorada e em cinco delas determinadas a disponibilidade de água para as plantas e a densidade do solo. As glebas estão situadas em áreas de Latossolo e Cambissolo e em uma gleba de cada classe foi realizado estudo da distribuição do sistema radicular do café no perfil do solo. A umidade foi monitorada no período de abril de 2008 a fevereiro de 2009, com frequência de 30 a 40 dias, amostradas as profundidades de 0,$2 ; 0,4 ; 0,8 ; 1,2$ e 1,6 m nas posições linha e entrelinha da cultura. Observou-se que a umidade do solo é menor na linha da cultura em relação à entrelinha. A classe de solo e a idade da lavoura também influenciaram a umidade do solo e a disponibilidade de água para as plantas. O sistema radicular do cafeeiro atingiu a camada de 1,5 a 1,7 m de profundidade de ambas as classes de solo estudadas. Por meio da análise de componentes principais separaram-se os 50 tratamentos em 4 grupos referentes à classe de solo e ao manejo.
\end{abstract}

Palavras-chave: perfil cultural, disponibilidade hídrica, sistema radicular, manejo conservacionista

\section{Water availability and landscape distinction for coffee cultivation}

\begin{abstract}
This study was conducted in the districts of São Roque de Minas and Vargem Bonita, MG, with the aim to distinguish landscapes for coffee growing, with higher water available to the crop. Soil moisture was monitored in eight plots of coffee, and in five of them being also determined water availability for plants and soil bulk density. The plots are located in areas of Latosols and Cambisols. In one plot of each soil class, the distribution of the root system of coffee in the soil profile was studied. Soil moisture was monitored from April 2008 to February 2009, in the interval of 30 to 40 days. The soil depths of $0.2,0.4,0.8,1.2$ and $1.6 \mathrm{~m}$ were sampled, in line and between the lines of the coffee. The combination of the five plots, two sampling positions (line and between the lines) and five depths, formed the 50 treatments used in the multivariate analysis. It was observed that soil moisture is lower in the line of coffee compared to between lines. The class of soil and plant age influence soil moisture and water availability to plants. The root system of coffee reached the depth of 1.5 to $1.7 \mathrm{~m}$, in both studied soil classes. The 50 treatments were grouped into 4 , by means of the principal component analysis, according to the soil class and management.
\end{abstract}

Key words: cultural profile, water availability, root system, conservation management

Instituto Federal de Educação, Ciência e Tecnologia de Mato Grosso - Campus Cáceres, Av. dos Ramires, s/n, Bairro Distrito Industrial, CEP 78.200-000, Cáceres, MT. Fone: (65) 3221-2600, Ramal 2667. E-mail: milson.serafim@cas.ifmt.edu.br

2 DCS/UFLA, C.P. 3037, CEP 37200-000, Lavras, MG. Fone (35) 3829-1600. E-mail: jmlima@dcs.ufla.br; geraldooliveira@dcs.ufla.br; brunom@dcs.ufla.br ${ }^{3}$ Depto. de Estatística/UFPR, C.P. 19.081, CEP 81.531-990, Bairro Jardim das Américas, Curitiba, PR. Fone: (41) 3361 3573. E-mail: walmes@ufpr.br ${ }^{4}$ Instituto Federal de Educação, Ciência e Tecnologia do Norte de Minas, Campus Almenara, CEP 39900-000, Almenara, MG. Email: vico.lima@ifnmg.edu.br 


\section{INTRODUÇÃO}

É comum, na cafeicultura, o produtor adotar tecnologias conhecidas ou desenvolver suas próprias tecnologias visando reduzir as limitações de clima e solo à cultura (Petek \& Patrício 2007) como é o caso da irrigação. Na Região do Alto São Francisco, a exemplo da Região do Triângulo Mineiro onde as chuvas são insuficientes ou mal-distribuídas durante o ano, a cafeicultura tem sua viabilidade atrelada à recomendação de irrigação (Fialho et al., 2010).

Conhecer a variabilidade espacial e temporal da disponibilidade hídrica dos solos é de suma importância na quantificação das necessidades hídricas dos vegetais; no entanto, determinações diretas e com a frequência indispensável a este parâmetro são bastante difíceis e trabalhosas em razão do seu comportamento dinâmico, que resulta em grande variabilidade espacial e temporal no solo (Vieira et al., 2010).

$\mathrm{O}$ armazenamento de água a ser considerado nos estudos de balanço hídrico depende da profundidade de exploração do sistema radicular no solo. Como a cultura do cafeeiro explora diferentes profundidades de solo em função de seu estádio de desenvolvimento, características fisiológicas e atributos do solo, a capacidade de água disponível (CAD) está sempre sujeita a uma variação contínua ao longo dos anos e das estações do ano (Pereira, 2005).

$\mathrm{O}$ desenvolvimento radicular depende de vários atributos relacionados à estrutura do solo, sendo difícil estabelecer, de forma isolada, o efeito desses atributos sobre o crescimento das plantas. A distinção de ambientes empregando-se técnicas de análise multivariada, integra vários desses atributos, o que favorece a discriminação daqueles mais favoráveis ao desenvolvimento das plantas (Kaiser et al., 2009; Sena et al., 2002).

O armazenamento de água no solo varia em razão da quantidade de água que infiltra e dos fatores que contribuem para que esta permaneça armazenada ao alcance do sistema radicular, o que é influenciado pelas propriedades físicas, mecânicas e hídricas do solo e por fatores locais, como a percentagem de cobertura da vegetação do solo (Castro, 2001). Isto evidencia a estreita relação das práticas de manejo com os fatores que determinam o armazenamento de água no solo.

Neste sentido há, por parte do cafeicultor, muita disposição de adotar, adaptar ou desenvolver suas próprias tecnologias para contornar limitações edafoclimáticas em suas lavouras. Um exemplo desta resposta é o sistema de cultivo conservacionista, desenvolvido na Região Fisiográfica do Alto São Francisco, MG, municípios de São Roque de Minas, Vargem Bonita, Piumhi e outros.

Os solos, de acordo com suas variações pedogenéticas, apresentam comportamento diferenciado quanto à dinâmica e ao armazenamento de água. Neste sentido, desenvolveu-se este trabalho com o objetivo de distinguir ambientes mais favoráveis à lavoura cafeeira quanto ao potencial de fornecer água para as plantas, em áreas de Latossolos e Cambissolos, com base nas variações de armazenamento ao longo do ano, na disponibilidade hídrica para a cultura e na densidade do solo.

\section{Material e Métodos}

O experimento foi realizado em solos com lavoura cafeeira (Coffea arabica L.) na Região fisiográfica do Alto São Francisco, Estado de Minas Gerais, Municípios de São Roque de Minas e Vargem Bonita. Para o estudo foram selecionadas oito glebas distribuídas em quatro fazendas: Curimba, AP Central, AP3 e AP2; as três primeiras se situam no Município de São Roque de Minas e a última no Município de Vargem Bonita, MG. Outras informações sobre os locais de estudo são apresentadas na Tabela 1. Para definição dos locais de estudo foram levadas em conta as unidades de solo predominantes na região e escolhidas áreas de Latossolos e Cambissolos com lavouras de diferentes idades. Na gleba AP Central/LVd foram aplicadas $48 \mathrm{t}$ de gesso na lavoura e nas demais foram aplicadas $28 \mathrm{t}$ em superfície, na linha de plantio.

Tabela 1. Descrição das glebas de estudo, local, posição na paisagem, idade da lavoura, espaçamento de plantio e declividade do terreno

\begin{tabular}{|c|c|c|c|c|}
\hline $\begin{array}{c}\text { Fazenda/ } \\
\text { Gleba/Idade }{ }^{1}\end{array}$ & $\begin{array}{c}\text { Posição na } \\
\text { paisagem }\end{array}$ & $\begin{array}{c}\text { Idade da } \\
\text { lavoura }^{2} \text { (anos) }\end{array}$ & $\begin{array}{c}\text { Espaçamento } \\
\text { (m) }\end{array}$ & $\begin{array}{l}D^{4} \\
(\%)\end{array}$ \\
\hline Curimba/LVAc ${ }_{3,5}$ & topo & $3,5-4,5$ & $2,5 \times 0,65$ & 4 a 7 \\
\hline Curimba/ $\mathrm{LVd}_{3,5}$ & terço médio & 3,5 & $2,5 \times 0,65$ & 9 a 14 \\
\hline AP Central//LVd ${ }_{8,5}$ & topo & & $2,5 x$ & 5 a 8 \\
\hline $\mathrm{AP} 3 / \mathrm{LVd}_{1,5}$ & topo & 1,5 & $2,5 x$ & 3 a 5 \\
\hline $\mathrm{AP} 2 / \mathrm{CXbd}_{1,5}$ & terço inferior & $1,5-2,5$ & $2,5 \times 0,65$ & 25 a 30 \\
\hline AP $2 / \mathrm{LVd}_{1,5}$ & topo & $1,5-2,5$ & $2,5 \times 0,65$ & 4 a 8 \\
\hline AP $2 / \mathrm{CXbd}_{0,5}$ & terço médio & 0,5 & $2,5 \times 0,65$ & 20 a 30 \\
\hline AP $2 / \operatorname{LVd}_{0,5}$ & topo & $0,5-1,5$ & $2,5 \times 0,65$ & 3 a 5 \\
\hline
\end{tabular}

${ }^{1}$ Fazenda (local da coleta), Gleba (classe de solo no SiBCS) e idade da lavoura no inicio do estudo; ${ }^{2}$ Idade da lavoura no início e no final do estudo; $\mathrm{D}^{4}$ - declividade do terreno

Todas as lavouras são manejadas em sistema conservacionista de cultivo, que consiste na aplicação de altas doses de gesso na linha, cultivo de braquiária (Urochloa sp.) nas entrelinhas da cultura, plantio da lavoura no mês de novembro, revolvimento do solo no sulco até $0,6 \mathrm{~m}$ de profundidade, correção da fertilidade do solo no sulco de plantio e adoção de um rigoroso programa de monitoramento do estado nutricional das plantas via análise foliar, duas ou três vezes ao ano (Serafim et al., 2011).

O monitoramento da umidade foi realizado no período de abril de 2008 a fevereiro de 2009, com coletas espaçadas 30 a 40 dias, totalizando 10 amostragens ao longo do período, exceto para a gleba $\mathrm{CXbd}_{1.5}$ que teve três amostragens adicionais. $\mathrm{O}$ delineamento experimental foi inteiramente casualizado (DIC) arranjado no esquema fatorial $2 \times 5$, sendo duas posições (linha e entrelinha), cinco profundidades (20,40,80, 120 e $150 \mathrm{~cm})$, com três repetições. Cada ponto amostral foi alocado aleatoriamente na gleba e as coletas de cada data foram feitas em um intervalo de dois metros anterior ou posterior a este ponto, no sentido da linha da cultura.

Para a coleta foram utilizados trado tipo holandês e cápsulas de alumínio com tampa, com 7,5 $\mathrm{cm}$ de diâmetro e $8,5 \mathrm{~cm}$ de altura; após a coleta as latas eram vedadas com fita adesiva e encaminhadas ao laboratório; enfim, a umidade gravimétrica foi determinada em estufa a $105^{\circ} \mathrm{C}$, por $24 \mathrm{~h}$.

Os valores do conteúdo de água nas tensões 6, 100 e 1500 $\mathrm{kPa}$ foram obtidos a partir da curva de retenção de água do 
solo; as curvas de cada gleba foram determinadas para as amostras com estrutura preservada, coletadas em trincheiras com 3 repetições nas profundidades de 0,$2 ; 0,4 ; 0,8 ; 1,2$ e 1,6 $\mathrm{m}$; as amostras preservadas foram obtidas em anéis $(0,064 \mathrm{~m}$ de diâmetro por $0,025 \mathrm{~m}$ de altura) e os demais procedimentos, segundo EMBRAPA (1997). Essas amostras foram utilizadas na determinação da densidade do solo (EMBRAPA, 1997).

$\mathrm{O}$ ajuste das curvas foi feito pelo conteúdo volumétrico de água $(\theta)$ em função da tensão da água no solo (h) empregandose o modelo proposto por Genuchten (1980) e se utilizando o método dos quadrados mínimos, Eq. 1:

$$
\theta=\left(\theta_{\text {sat }}-\theta_{\text {res }}\right)\left[1+(\alpha h)^{\mathrm{n}}\right]^{-\mathrm{m}}+\theta_{\text {res }}
$$

sendo:

$\mathrm{h} \quad$ - tensão da água no solo $(\mathrm{kPa})$

$\theta \quad$ - conteúdo de água $\left(\mathrm{m}^{3} \mathrm{~m}^{-3}\right)$

$\theta_{\text {sat }} \quad$ - conteúdo de água na saturação $\left(\mathrm{m}^{3} \mathrm{~m}^{-3}\right)$

$\theta_{\text {res }}^{\text {sat }}$ - conteúdo de água no ponto de murcha permanente $\left(\mathrm{m}^{3} \mathrm{~m}^{-3}\right)$

e m, n e $\alpha$ - parâmetros de ajuste do modelo

A disponibilidade hídrica do solo para a cultura em cada data de coleta foi dividida em água prontamente disponível (APD) (Oliveira et al., 2004) e água disponível (AD) em que a umidade do solo acima da $U_{100}$ foi considerada ótima para a cultura visto que permite o metabolismo pleno das plantas; a umidade do solo entre $U_{100}$ e $U_{1500}$ é aquela em que ocorre decréscimo do metabolismo na medida em que a umidade se aproxima de $\mathrm{U}_{1500}$. Valores de umidade inferiores a $\mathrm{U}_{1500}$ foram considerados água indisponível para as plantas.

AAPD foi determinada, nas diferentes profundidades, pela diferença entre a umidade do solo no momento da amostragem (U) e a umidade do solo na tensão de $100 \mathrm{kPa}\left(\mathrm{U}_{100}\right)$ e a $\mathrm{AD}$ determinada pela diferença entre $U$ e a umidade do solo na tensão de $1500 \mathrm{kPa}\left(\mathrm{U}_{1500}\right)$.

Para a apresentação dessa disponibilidade hídrica foi estimada a umidade padronizada (UP) empregando-se a Eq. 2, conforme a qual os valores de umidade padronizada acima de 1 correspondem a APD, valores entre 0 e 1 indicam a AD e valores menores que 0 se referem à água indisponível, ou seja, umidade abaixo do ponto de murcha permanente; enfim, os valores de UP foram lançados no gráfico em função das datas de coleta, de modo que permitisse visualizar a disponibilidade hídrica para a cultura em cada camada de solo estudada, nas diferentes datas.

$$
\mathrm{UP}=\frac{\left(\mathrm{U}-\mathrm{U}_{1500}\right)}{\left(\mathrm{U}_{100}-\mathrm{U}_{1500}\right)}
$$

Para avaliação do crescimento e da distribuição do sistema radicular foram escolhidas as glebas $\mathrm{LVd}_{3,5}$ e $\mathrm{CXbd}_{1,5}$, e empregado o método do perfil, descrito por Böhm (1979). Para caracterizar o volume de solo explorado pelas raízes a distribuição do sistema radicular das plantas foi avaliada por meio da abertura de uma trincheira paralela à linha de café, expondo as raízes de uma planta escolhida aleatoriamente de maneira que representasse o conjunto de plantas da gleba.

As raízes foram expostas através de jato de água e rolo escarificador. O perfil foi dividido em quadrículas de $0,1 \mathrm{x}$ $0,1 \mathrm{~m}$, feitas com barbante em contato com o solo. Efetuouse o desenho do formato natural em que se encontravam as raízes, obtendo-se o perfil de distribuição radicular da planta de cafeeiro.

A descrição (desenho) foi feita em uma área de $0,2 \mathrm{~m}$ de altura e $0,4 \mathrm{~m}$ de largura na camada de 1,5 a $1,7 \mathrm{~m}$ de profundidade correspondente à maior profundidade de estudo da umidade do solo. Admitiu-se, com isto, que a presença de raízes nas camadas anteriores foi igual ou maior que as quantidades encontradas na camada de estudo apresentada, já que não foi identificada disposição anômala de raízes no perfil.

Com vista à classificação da densidade de raízes na área do desenho, seguiu-se a metodologia proposta no Manual de Pedologia (IBGE, 2007). Utilizou-se a divisão em classes de tamanho com base no seu diâmetro, donde: $<1 \mathrm{~mm}$ - muito finas; $1 \mathrm{a}<2 \mathrm{~mm}$ - finas; $2 \mathrm{a}<5 \mathrm{~mm}$ - grossas e $>10 \mathrm{~mm}$ muito grossas.

Fez-se a estimativa da quantidade de raízes com base no número de raízes por unidade de área (U.A.) do perfil do solo, conforme discriminado: $<1$ por U.A. - poucas; 1 a 5 por U.A. - comuns e $>5$ por U.A. - abundantes. $\mathrm{O}$ tamanho das referidas unidades de área (U.A.) foi definido em função da classe de tamanho das raízes, sendo: muito finas e finas $0,01 \mathrm{dm}^{2}$; médias e grossas $1 \mathrm{dm}^{2}$ e muito grossas $100 \mathrm{dm}^{2}$.

Os dados obtidos para umidade foram submetidos às análises de variância e, quando significativos pelo teste $\mathrm{F}$ (5\%) aplicou-se o teste de média (Tukey 0,05) utilizando-se o software estatístico Sisvar (Ferreira, 2011).

Para o estudo de agrupamento dos ambientes semelhantes realizou-se a estatística descritiva dos resultados visando à obtenção das médias dos atributos de cada tratamento. Foi considerado tratamento cada combinação de posição (linha ou entrelinha) com as camadas estudadas do solo $(0,2 ; 0,4$; 0,$8 ; 1,2 ; 1,6 \mathrm{~m}$ ) em cada uma das 5 glebas, o que totalizou 50 tratamentos (Tabela 2).

A análise de componentes principais foi utilizada de acordo com Souza \& Paiva (2001) para a avaliação das características dos solos nos conjuntos de atributos físicos. Como critério, adotou-se o menor número de componentes principais contanto que esses componentes envolvessem um mínimo de $80 \%$ da variação total (Cruz et al., 2004).

O processo de agrupamento envolveu, basicamente, duas etapas: no início foi caracterizada a dissimilaridade entre os tratamentos por meio da distância generalizada de Mahalanobis adotando-se, depois, técnicas de agrupamento para a formação dos grupos (Método de Tocher e Dispersão Gráfica pelos Componentes Principais) segundo metodologia descrita por Cruz et al. (2004). A importância relativa das variáveis na determinação dos valores das distâncias entre os tratamentos foi dada pelo método de Singh (1981). Todas as análises foram realizadas utilizando-se o programa Genes, versão 2010 (Cruz, 2006).

O conjunto de características usadas para esta separação foi composto da densidade do solo, da umidade volumétrica 
Tabela 2. Lista dos 50 tratamentos $(\mathrm{T})$ empregados na análise multivariada correspondentes às cinco glebas $(\mathrm{G})$ estudadas $\left(\mathrm{LVd}_{3,5} ; \mathrm{CXbd}_{3,5} ; \mathrm{LVd}_{1,5} ; \mathrm{LVd}_{0,5 ;} \mathrm{CXbd}_{0,5}\right)$ nas posições linha e entrelinha (EL/L) nas profundidades $(\mathrm{P})$ de 0,$2 ; 0,4 ; 0,8 ; 1,2 ; 1,6 \mathrm{~m}$

\begin{tabular}{|c|c|c|c|c|c|c|c|c|c|c|c|}
\hline$T$ & $\bar{G}$ & $E \mathrm{EL} / \mathrm{L}$ & P. & $\mathbf{T}$ & $\bar{G}$ & $\mathrm{EL} / \mathrm{L}$ & P. & $\mathrm{T}$ & $\bar{G}$ & $E \mathrm{EL} / \mathrm{L}$ & $P$ \\
\hline 1 & $\mathrm{CXbd}_{3,5}$ & EL & 0,2 & 18 & $\operatorname{LVd}_{1.5}$ & EL & 1,2 & 35 & $\mathrm{CXbd}_{3,5}$ & L & 0,4 \\
\hline 2 & $\mathrm{LVd}_{3,5}$ & EL & 0,2 & 19 & $\mathrm{cXbd}_{0,5}$ & $\mathrm{EL}$ & 1,2 & 36 & $\mathrm{LVd}_{3,5}$ & L & 0,8 \\
\hline 3 & $\operatorname{LVd}_{1.5}$ & $\mathrm{EL}$ & 0,2 & 20 & $\mathrm{LVd}_{0,5}$ & $\mathrm{EL}$ & 1,2 & 37 & $\mathrm{LVd}_{1,5}$ & L & 0,8 \\
\hline 4 & $\mathrm{CXbd}_{0,5}$ & $\mathrm{EL}$ & 0,2 & 21 & $\mathrm{CXbd}_{3,5}$ & $\mathrm{EL}$ & 1,6 & 38 & $\mathrm{cXbd}_{0.5}$ & L & 0,8 \\
\hline 5 & $\mathrm{LVd}_{0,5}$ & $\mathrm{EL}$ & 0,2 & 22 & $\mathrm{LVd}_{3,5}$ & $\mathrm{EL}$ & 1,6 & 39 & $\mathrm{LVd}_{0,5}$ & L & 0,8 \\
\hline 6 & $\mathrm{CXbd}_{35}$ & $\mathrm{EL}$ & 0,4 & 23 & $\mathrm{LVd}_{1,5}$ & $\mathrm{EL}$ & 1,6 & 40 & $\mathrm{LVd}_{0.5}$ & L & 0,8 \\
\hline 7 & $\mathrm{LVd}_{3,5}$ & $\mathrm{EL}$ & 0,4 & 24 & $\mathrm{CXbd}_{0,5}$ & $\mathrm{EL}$ & 1,6 & 41 & $\mathrm{cXbd}_{3,5}$ & L & 1,2 \\
\hline 8 & $\mathrm{LVd}_{1,5}$ & $\mathrm{EL}$ & 0,4 & 25 & $\mathrm{LVd}_{0,5}$ & $\mathrm{EL}$ & 1,6 & 42 & $\mathrm{LVd}_{35}$ & L & 1,2 \\
\hline 9 & $\mathrm{cXbd}_{0,5}$ & EL & 0,4 & 26 & $\mathrm{cXbd}_{3,5}$ & $\mathrm{~L}$ & 0,2 & 43 & $\mathrm{LVd}_{1,5}$ & L & 1,2 \\
\hline 10 & $\mathrm{LVd}_{0,5}$ & EL & 0,4 & 27 & $\operatorname{LVd}_{3.5}$ & L & 0,2 & 44 & $\operatorname{cXbd}_{0,5}$ & L & 1,2 \\
\hline 11 & $\mathrm{cXbd}_{3,5}$ & $\mathrm{EL}$ & 0,8 & 28 & $\operatorname{LVd}_{1.5}$ & L & 0,2 & 45 & $\mathrm{LVd}_{0,5}$ & L & 1,2 \\
\hline 12 & $\mathrm{LVd}_{3,5}$ & $\mathrm{EL}$ & 0,8 & 29 & $\mathrm{CXbd}_{0.5}$ & $\mathrm{~L}$ & 0,2 & 46 & $\mathrm{cXbd}_{3,5}$ & L & 1,6 \\
\hline 13 & $\mathrm{LVd}_{1,5}$ & $\mathrm{EL}$ & 0,8 & 30 & $\mathrm{LVd}_{0,5}$ & $\mathrm{~L}$ & 0,2 & 47 & $\mathrm{LVd}_{3,5}$ & L & 1,6 \\
\hline 14 & $\mathrm{CXbd}_{0,5}$ & $\mathrm{EL}$ & 0,8 & 31 & $\mathrm{CXbd}_{35}$ & $\mathrm{~L}$ & 0,4 & 48 & $\mathrm{LVd}_{15}$ & L & 1,6 \\
\hline 15 & $\mathrm{LVd}_{0,5}$ & EL & 0,8 & 32 & $\operatorname{LVd}_{3,5}$ & $\mathrm{~L}$ & 0,4 & 49 & $\mathrm{cXbd}_{0,5}$ & L & 1,6 \\
\hline 16 & $\mathrm{CXbd}_{35}$ & $\mathrm{EL}$ & 1,2 & 33 & $\operatorname{LVd}_{1,5}$ & L & 0,4 & 50 & $\mathrm{LVd}_{0,5}$ & L & 1,6 \\
\hline 17 & $\mathrm{LVd}_{3,5}$ & EL & 1,2 & 34 & $\mathrm{CXbd}_{0,5}$ & $\mathrm{~L}$ & 0,4 & & & & \\
\hline
\end{tabular}

observada nas datas de coleta e da umidade volumétrica correspondente às tensões de 6, 100 e $1500 \mathrm{kPa}$. Desta maneira, procurou-se reunir os tratamentos representados pelos pontos de estudo com base na similaridade dos atributos físico-hídricos do solo.

\section{Resultados E Discussão}

A umidade média do solo ao longo do ano até a profundidade de 1,6 m é dependente da posição de coleta da amostra na linha ou na entrelinha do cafeeiro. Entre as oito glebas estudadas seis apresentaram diferença significativa de umidade para as posições linha e entrelinha (Tabela 3); isto indica que na linha da cultura ocorre o uso mais intenso da água devido à presença de maior número de raízes da planta de cafeeiro, fato também observado para eucalipto, por Leite et al. (1999). As duas glebas que não apresentaram diferença significativa de umidade das posições linha e entrelinha estão localizadas na mesma rampa (encosta). Esta semelhança se deve à ocorrência de chuvas pouco antes da amostragem uniformizando a umidade nas duas posições amostradas.

Tabela 3. Média dos valores de umidade até 1,6 m de profundidade, proveniente dos valores de umidade obtidos nas camadas de 0,$2 ; 0,4 ; 0,8 ; 1,2$ e 1,6 m, com 10 coletas no período de 24/04/2008 a 10/02/2009, nas posições linha e entrelinha da lavoura de cafeeiro, em Latossolos e Cambissolos, de São Roque de Minas e Vargem Bonita, MG

\begin{tabular}{|c|c|c|c|c|}
\hline \multirow{2}{*}{ Gleba } & \multirow{2}{*}{ Idade } & \multirow{2}{*}{ Solo } & \multicolumn{2}{|c|}{ Umidade $\left(\mathrm{g} \mathrm{g}^{-1}\right)$} \\
\hline & & & $\mathbf{L}$ & EL \\
\hline $\mathrm{CXbd}_{3,5}$ & $3,5-4,5$ & LVA & $34,6 b^{1}$ & $36,2 a$ \\
\hline $\mathrm{LVd}_{3,5}$ & $3,5-4,5$ & LVd & $35,4 \mathrm{~b}$ & $37,9 a$ \\
\hline $\mathrm{LVd}_{8,5}$ & $8,5-9,5$ & LVd & $34,9 \mathrm{~b}$ & $35,5 a$ \\
\hline $\mathrm{LVd}_{1,5}$ & $1,5-2,5$ & LVd & $33,2 \mathrm{~b}$ & $35,7 a$ \\
\hline $\mathrm{CXbd}_{1,5}$ & $1,5-2,5$ & CXbd & $30,6 \mathrm{a}$ & $30,0 a$ \\
\hline $\operatorname{LVd}_{1,5}$ & $1,5-2,5$ & LVd & $35,0 \mathrm{a}$ & 35,4 \\
\hline $\mathrm{CXbd}_{0,5}$ & $0,5-1,5$ & CXbd & $35,3 \mathrm{a}$ & $35,1 a$ \\
\hline $\mathrm{LVd}_{0,5}$ & $0,5-1,5$ & LVd & $34,6 \mathrm{~b}$ & $36,6 \mathrm{a}$ \\
\hline
\end{tabular}

${ }^{1}$ Médias seguidas de mesma letra na linha, não se diferenciam pelo teste de Tukey a 0,05
A tendência de umidade mais elevada na entrelinha da cultura em relação à linha tende a ficar mais pronunciada nas maiores profundidades. Para facilitar a visualização os valores de umidade gravimétrica (\%) das cinco camadas estudadas para a Gleba LVA ${ }_{3,5}$ foram lançados no gráfico (Figura 1). Dispensouse a apresentação de figura semelhante para todas as glebas por ser redundante com os dados das tabelas apresentadas. $\mathrm{Na}$ camada superficial a braquiária manejada com roçadas, rolofaca ou herbicidas em subdose não consumiu água de forma considerável; contudo, a arquitetura do sistema radicular do cafeeiro indica raízes horizontais que ultrapassam a projeção da copa, constituindo fator de uniformização da umidade da camada superficial, para uma cultura com espaçamento de 2,5 $\mathrm{m}$ entre as linhas.

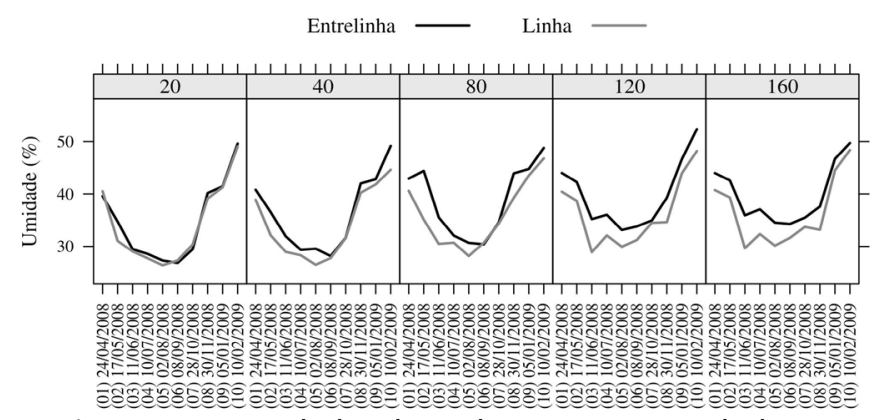

Figura 1. Umidade do solo na posição linha e entrelinha nas profundidades de 0,$2 ; 0,4 ; 0,8 ; 1,2$ e $1,6 \mathrm{~m}$, no período de abril de 2008 a fevereiro de 2009, no Município de São Roque de Minas, MG

Para todas as glebas estudadas a umidade do solo no perfil apresenta gradiente crescente com a profundidade sendo que a umidade a 1,2 m não difere significativamente daquela a 1,6 m. Para as glebas $\operatorname{LVd}_{3,5}, \mathrm{CXbd}_{1,5}$ e $\mathrm{LVd}_{0,5}$, a partir de $0,8 \mathrm{~m}$ não há diferença de umidade (Tabela 4). Mencionados resultados mostram que o efeito do período seco é mais pronunciado até a profundidade de $0,8 \mathrm{~m}$. Plantas com sistema radicular abaixo desta profundidade tornam-se menos susceptíveis ao déficit hídrico (Souza et al., 2008). 
Tabela 4. Médias de umidade do solo sob café nas profundidades de 0,$2 ; 0,4 ; 0,8 ; 1,2$ e 1,6 m, de Latossolos e Cambissolos, em São Roque de Minas e Vargem Bonita, MG

\begin{tabular}{|c|c|c|c|c|c|c|c|}
\hline \multirow[b]{2}{*}{ Local } & \multirow{2}{*}{$\begin{array}{l}\text { Idade } \\
\text { (anos) }\end{array}$} & \multirow[b]{2}{*}{ Solo } & \multicolumn{5}{|c|}{ Profundidades (m) } \\
\hline & & & 0,2 & 0,4 & 0,8 & 1,2 & 1,6 \\
\hline $\mathrm{LVA}_{3,5}$ & $3,5-4,5$ & LVA & $33,36 c^{1}$ & $33,71 \mathrm{c}$ & $35,54 \mathrm{~b}$ & $36,98 \mathrm{a}$ & $37,28 \mathrm{a}$ \\
\hline $\mathrm{LVd}_{8,5}$ & $8,5-9,5$ & LVd & $33,95 \mathrm{c}$ & $34,25 \mathrm{c}$ & $35,26 b$ & $36,04 \mathrm{a}$ & $36,43 \mathrm{a}$ \\
\hline $\mathrm{LVd}_{1,5}$ & $1,5-2,5$ & LVd & $31,47 \mathrm{e}$ & $32,53 \mathrm{~d}$ & $34,50 \mathrm{c}$ & $36,52 \mathrm{~b}$ & $37,38 \mathrm{a}$ \\
\hline $\mathrm{CXbd}_{1,5}$ & $1,5-2,5$ & CXbd & $29,12 b$ & $29,52 a b$ & $30,31 \mathrm{ab}$ & $30,40 a b$ & $32,16 \mathrm{a}$ \\
\hline $\operatorname{LVd}_{0,5}$ & $0,5-1,5$ & LVd & $33,63 \mathrm{~b}$ & $33,98 \mathrm{~b}$ & $36,09 a$ & $36,26 \mathrm{a}$ & $35,90 \mathrm{a}$ \\
\hline
\end{tabular}

${ }^{1}$ Médias seguidas de mesma letra na linha não diferem pelo teste Tukey 0,05

Tabela 5. Médias de umidade em diferentes datas ao longo do ano, nas profundidades de 0,$2 ; 0,4 ; 0,8 ; 1,2$ e $1,6 \mathrm{~m}$ do perfil do solo, sob cafeeiro, no período de um ano, em Latossolos e Cambissolos, em São Roque de Minas e Vargem Bonita, MG

\begin{tabular}{|c|c|c|c|c|c|c|c|c|c|c|}
\hline \multirow{2}{*}{ Data } & \multicolumn{10}{|c|}{ Profundidades (m) } \\
\hline & 0,2 & 0,4 & 0,8 & 1,2 & 1,6 & 0,2 & 0,4 & 0,8 & 1,2 & 1,6 \\
\hline $24 / 04 / 08$ & $39,0 \mathrm{a}$ & $38,6 \mathrm{a}$ & $39,2 \mathrm{a}$ & $39,7 \mathrm{a}$ & $40,2 \mathrm{a}$ & $40,1 \mathrm{a}$ & $39,8 \mathrm{a}$ & $41,8 \mathrm{a}$ & $42,2 \mathrm{a}$ & $42,4 \mathrm{a}$ \\
\hline $11 / 06 / 08$ & $29,9 \mathrm{C}$ & $30,5 \mathrm{bc}$ & 32,2 ba & 32,9 ba & $34,5 \mathrm{a}$ & $29,3 \mathrm{~b}$ & $30,4 a b$ & $33,0 \mathrm{a}$ & $32,1 \mathrm{a}$ & $32,8 \mathrm{a}$ \\
\hline $10 / 07 / 08$ & $28,9 \mathrm{C}$ & 29,9 bc & $32,3 b$ & $34,8 \mathrm{a}$ & $36,2 \mathrm{a}$ & $28,2 \mathrm{C}$ & $28,8 \mathrm{bc}$ & $31,4 \mathrm{~b}$ & $34,1 \mathrm{a}$ & $34,7 \mathrm{a}$ \\
\hline 02/08/08 & $29,9 \mathrm{~b}$ & $28,9 \mathrm{~b}$ & $30,8 b$ & $33,4 \mathrm{a}$ & $35,1 \mathrm{a}$ & $26,9 \mathrm{c}$ & $28,0 \mathrm{C}$ & 29,4 bc & $31,5 a b$ & $32,3 \mathrm{a}$ \\
\hline $30 / 11 / 08$ & $36,7 \mathrm{c}$ & $37,6 \mathrm{c}$ & $38,1 \mathrm{bc}$ & $40,5 a b$ & $41,1 \mathrm{a}$ & $39,6 \mathrm{a}$ & $41,1 \mathrm{a}$ & $41,6 \mathrm{a}$ & $36,9 \mathrm{~b}$ & $35,4 \mathrm{a}$ \\
\hline 05/01/09 & $40,8 \mathrm{a}$ & $40,8 \mathrm{a}$ & $40,5 \mathrm{a}$ & $41,6 \mathrm{a}$ & $42,1 \mathrm{a}$ & $41,4 \mathrm{C}$ & $42,3 \mathrm{bc}$ & $44,2 a b$ & $45,3 \mathrm{a}$ & $45,6 \mathrm{a}$ \\
\hline $10 / 02 / 09$ & $38,2 \mathrm{a}$ & $38,5 \mathrm{a}$ & $38,5 \mathrm{a}$ & $39,7 \mathrm{a}$ & $40,0 \mathrm{a}$ & $49,3 a b$ & $46,9 \mathrm{~b}$ & $47,8 a b$ & $50,3 \mathrm{a}$ & $49,1 \mathrm{ab}$ \\
\hline & \multicolumn{5}{|c|}{$\mathrm{LVd}-1,5$ a 2,5 ano } & \multicolumn{5}{|c|}{ CXbd- 1,5 a 2,5 ano } \\
\hline $24 / 04 / 08$ & $39,3 \mathrm{a}$ & $37,8 \mathrm{a}$ & $38,4 \mathrm{a}$ & $39,1 \mathrm{a}$ & $39,2 \mathrm{a}$ & $35,1 \mathrm{a}$ & $35,5 \mathrm{a}$ & $34,8 \mathrm{a}$ & $34,6 \mathrm{a}$ & $29,8 \mathrm{a}$ \\
\hline $17 / 05 / 08$ & $31,0 \mathrm{c}$ & $32,6 \mathrm{bc}$ & $35,4 \mathrm{~b}$ & $38,8 \mathrm{a}$ & $40,2 \mathrm{a}$ & $29,0 \mathrm{a}$ & $30,5 \mathrm{a}$ & $33,0 \mathrm{a}$ & $32,4 \mathrm{a}$ & $30,5 \mathrm{a}$ \\
\hline $28 / 10 / 08$ & $35,1 \mathrm{~b}$ & $35,7 \mathrm{~b}$ & $38,3 a b$ & $39,2 \mathrm{a}$ & $40,8 \mathrm{a}$ & $30,2 \mathrm{a}$ & $32,2 \mathrm{a}$ & $33,1 \mathrm{a}$ & $28,1 \mathrm{a}$ & $27,4 \mathrm{a}$ \\
\hline $30 / 11 / 08$ & $40,2 \mathrm{a}$ & $42,2 \mathrm{a}$ & $41,7 \mathrm{a}$ & $40,4 \mathrm{a}$ & $41,0 \mathrm{a}$ & $32,5 \mathrm{a}$ & $33,7 \mathrm{a}$ & $33,8 \mathrm{a}$ & $28,9 \mathrm{a}$ & $30,0 \mathrm{a}$ \\
\hline 05/01/09 & $37,1 \mathrm{~b}$ & 39,0 ba & $37,0 \mathrm{~b}$ & 39,5 ba & $40,6 \mathrm{a}$ & $39,9 \mathrm{~b}$ & $40,3 b$ & $47,0 \mathrm{a}$ & $41,1 \mathrm{ab}$ & $40,8 a b$ \\
\hline $10 / 02 / 09$ & $37,7 \mathrm{c}$ & $38,9 \mathrm{c}$ & 39,6 bc & $42,4 a b$ & $43,6 \mathrm{a}$ & $34,7 \mathrm{a}$ & $34,2 \mathrm{a}$ & $32,8 a b$ & $29,0 \mathrm{ab}$ & $26,2 \mathrm{~b}$ \\
\hline $16 / 06 / 09$ & - & - & - & - & - & $27,0 \mathrm{a}$ & $29,0 \mathrm{a}$ & $31,2 \mathrm{a}$ & $32,2 \mathrm{a}$ & $31,8 \mathrm{a}$ \\
\hline $14 / 07 / 09$ & - & - & - & - & - & $24,3 a$ & $24,9 a$ & $27,2 \mathrm{a}$ & $25,4 \mathrm{a}$ & $24,4 \mathrm{a}$ \\
\hline \multirow[t]{2}{*}{$07 / 09 / 09$} & - & - & - & - & - & $39,9 \mathrm{~b}$ & $40,3 b$ & $48,0 \mathrm{a}$ & $41,1 \mathrm{ab}$ & $40,8 a b$ \\
\hline & \multicolumn{5}{|c|}{$\mathrm{LVd}-0,5$ a 1,5 ano } & \multicolumn{5}{|c|}{ CXbd- 0,5 a 1,5 ano } \\
\hline $24 / 04 / 08$ & $37,3 \mathrm{a}$ & $37,9 \mathrm{a}$ & $38,5 \mathrm{a}$ & $39,2 \mathrm{a}$ & $39,7 \mathrm{a}$ & $38,2 \mathrm{a}$ & $37,9 \mathrm{a}$ & $38,8 \mathrm{a}$ & $37,5 a b$ & $37,9 \mathrm{~b}$ \\
\hline $17 / 05 / 08$ & $30,7 \mathrm{c}$ & $32,4 \mathrm{C}$ & $35,8 \mathrm{~b}$ & $42,7 \mathrm{a}$ & $40,0 \mathrm{a}$ & $30,9 \mathrm{c}$ & $33,3 b$ & 34,8 bv & $36,6 a b$ & $34,0 \mathrm{bc}$ \\
\hline $11 / 06 / 08$ & $28,2 \mathrm{~b}$ & $29,0 \mathrm{~b}$ & $33,7 \mathrm{a}$ & $32,3 \mathrm{a}$ & $33,5 \mathrm{a}$ & $28,8 \mathrm{bc}$ & $29,6 \mathrm{c}$ & $32,7 \mathrm{c}$ & $31,6 \mathrm{c}$ & $31,2 \mathrm{c}$ \\
\hline $10 / 07 / 08$ & $26,4 \mathrm{C}$ & $28,5 \mathrm{C}$ & $33,8 \mathrm{~b}$ & $37,4 \mathrm{a}$ & $38,8 \mathrm{a}$ & $29,1 \mathrm{~b}$ & $29,3 \mathrm{C}$ & $32,0 \mathrm{cV}$ & $34,1 \mathrm{bc}$ & $36,0 \mathrm{~b}$ \\
\hline $17 / 05 / 08$ & $30,1 \mathrm{c}$ & $32,3 \mathrm{c}$ & $35,0 \mathrm{~b}$ & $39,1 \mathrm{a}$ & $39,5 \mathrm{a}$ & $33,4 \mathrm{~b}$ & $33,5 b$ & $37,3 \mathrm{a}$ & $38,1 \mathrm{a}$ & $39,1 \mathrm{a}$ \\
\hline $11 / 06 / 08$ & $25,3 \mathrm{c}$ & $28,3 \mathrm{~b}$ & $31,3 \mathrm{a}$ & $31,4 \mathrm{a}$ & $32,3 \mathrm{a}$ & $30,1 \mathrm{~b}$ & 31,4 ba & $33,3 \mathrm{a}$ & 31,9 ba & 31,9 ba \\
\hline $10 / 07 / 08$ & $25,8 \mathrm{C}$ & $26,7 \mathrm{C}$ & $30,0 \mathrm{~b}$ & $35,3 \mathrm{a}$ & $37,0 \mathrm{a}$ & $29,1 \mathrm{~b}$ & 29,7 ba & $31,9 \mathrm{a}$ & 30,1 ba & 29,7 ba \\
\hline 02/08/08 & $25,5 \mathrm{~b}$ & $27,4 \mathrm{~b}$ & $29,7 a b$ & $32,0 \mathrm{a}$ & $34,2 \mathrm{a}$ & $27,3 \mathrm{c}$ & $28,2 \mathrm{C}$ & $28,6 \mathrm{C}$ & $31,6 \mathrm{~b}$ & $33,7 \mathrm{a}$ \\
\hline 08/09/08 & $27,3 \mathrm{~d}$ & $26,8 \mathrm{~cd}$ & $29,5 \mathrm{c}$ & $31,7 \mathrm{~b}$ & $34,1 \mathrm{a}$ & $29,2 \mathrm{cb}$ & $27,7 \mathrm{c}$ & $29,0 \mathrm{C}$ & $31,2 \mathrm{~b}$ & $32,5 \mathrm{a}$ \\
\hline $28 / 10 / 08$ & $31,7 \mathrm{c}$ & $32,4 \mathrm{cb}$ & 34,2 ba & $35,9 \mathrm{a}$ & $36,2 \mathrm{a}$ & $34,2 \mathrm{c}$ & $34,6 \mathrm{cb}$ & $35,4 \mathrm{cb}$ & $36,9 \mathrm{a}$ & 36,4 ba \\
\hline $30 / 11 / 08$ & $35,7 \mathrm{~b}$ & 36,3 ba & $36,8 \mathrm{ba}$ & 37,6 ba & $38,3 \mathrm{a}$ & $38,8 \mathrm{a}$ & $39,6 \mathrm{a}$ & 39,7 a & $40,1 \mathrm{a}$ & $40,5 \mathrm{a}$ \\
\hline $05 / 01 / 09$ & $39,6 \mathrm{~b}$ & $40,4 a b$ & $41,5 a b$ & $42,0 \mathrm{a}$ & $42,2 \mathrm{a}$ & $39,1 \mathrm{~b}$ & $39,2 \mathrm{~b}$ & 41,0 ba & $41,9 \mathrm{a}$ & $42,3 \mathrm{a}$ \\
\hline $10 / 02 / 09$ & $36,8 \mathrm{C}$ & $38,4 \mathrm{~b}$ & 39,9 ba & $40,5 \mathrm{ba}$ & $41,2 \mathrm{a}$ & $36,7 \mathrm{a}$ & $36,8 \mathrm{a}$ & $36,4 \mathrm{a}$ & $36,4 \mathrm{a}$ & $36,9 \mathrm{a}$ \\
\hline
\end{tabular}

${ }^{*}$ Médias seguidas de mesma letra na linha, não diferem pelo teste Tukey 0,05 
A comparação dos valores de umidade em cada data de coleta entre as camadas (Tabela 5) enfatiza as afirmações anteriores de que é na camada de $0,2 \mathrm{~m}$ onde ocorre a maior variação de umidade ao longo do ano, seguida da camada de 0,4 $\mathrm{m}$. Por fim, a camada de $0,8 \mathrm{~m}$ se diferencia significativamente das camadas de 1,2 e 1,6 m, somente em algumas datas do período seco em alguns locais indicando que a partir desta profundidade há uniformização da umidade, corroborando com Loyola \& Prevedello (2003).

Situações em que se observa a umidade de uma camada superior maior que nas camadas inferiores, foram relacionadas à ocorrência de chuvas anteriores à coleta, com volume ou tempo insuficiente para que a frente de umedecimento do solo atingisse as camadas inferiores. Dados desta natureza podem ser observados com mais frequência nas glebas de Cambissolo cujas características físicas retardam a redistribuição de água no perfil (Ottoni Filho, 2003; Menezes et al., 2009).

$\mathrm{O}$ estudo da disponibilidade hídrica por meio da umidade padronizada indica maior disponibilidade hídrica para a cultura nas camadas de 1,2 e 1,6 m (Figuras 2 e 3), corroborando com os resultados anteriores.

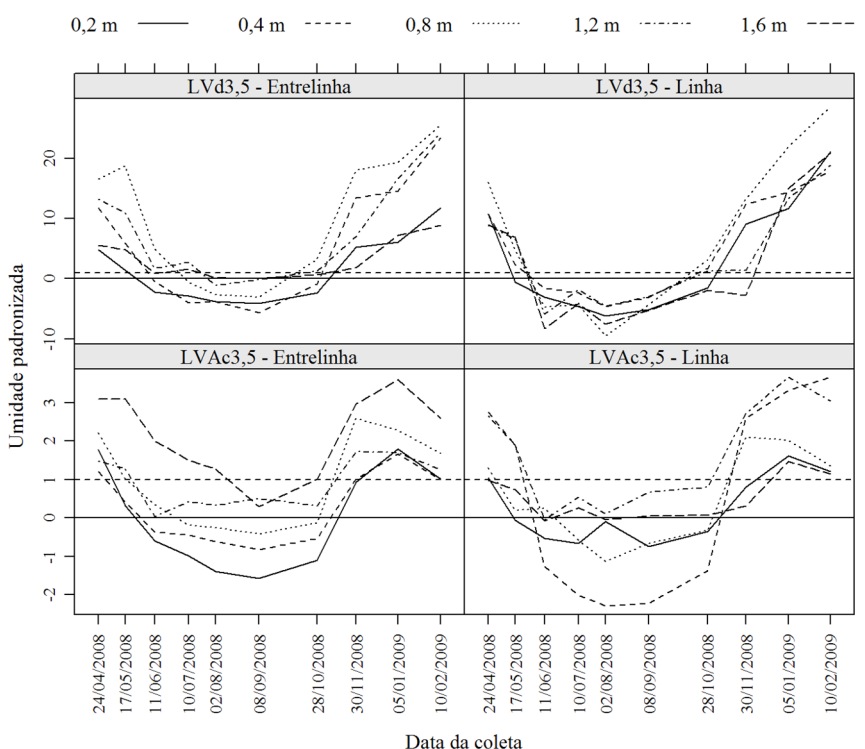

Figura 2. Disponibilidade hídrica para o cafeeiro ao longo do ano, na posição linha e entrelinha da cultura, nas profundidades de 0,$2 ; 0,4 ; 0,8 ; 1,2$ e 1,6 m, município de São Roque de Minas, MG

As lavouras de idade superior a 1,5 ano apresentaram maior disponibilidade hídrica na entrelinha em relação à linha. Os valores padronizados de umidade mais elevados em todo o perfil da entrelinha em relação à linha indicam o uso de água pela planta de café para todas as camadas estudadas. A comparação da disponibilidade hídrica foi feita entre lavouras da mesma idade haja vista que o tamanho da planta de café é um componente ativo no consumo de água (Leite et al., 1999).

A comparação das glebas $\mathrm{CXbd}_{3.5} \mathrm{e} \mathrm{LVd}_{3,5}$ enfatiza o efeito das classes de solo na disponibilidade hídrica. O solo na gleba $\mathrm{CXbd}_{3,5}$ apresentou maior disponibilidade hídrica em relação a $\operatorname{LVd}_{3,5}$ decorrente de sua estrutura tendendo a blocos, mais favorável ao armazenamento de água em tensões disponíveis à planta (Franzluebbers, 2002).

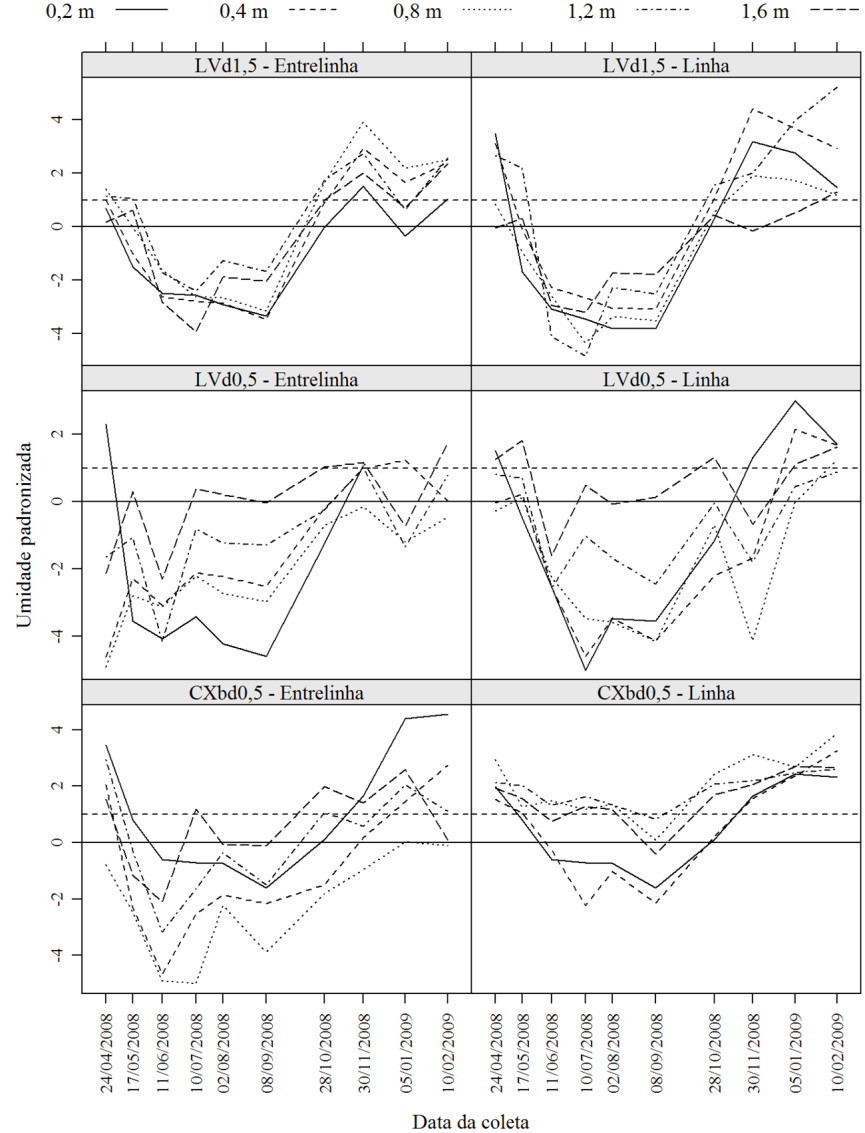

Figura 3. Disponibilidade hídrica para o cafeeiro ao longo do ano, na posição linha e entrelinha da cultura, nas profundidades de 0,$2 ; 0,4 ; 0,8 ; 1,2$ e 1,6 $\mathrm{m}$, município de Vargem Bonita, MG

O secamento mais intenso na linha da cultura até 1,6 m indica a presença de bulbo de secamento causado pela planta. Uma informação relevante a ser extraída é que as raízes presentes a 1,6 m são ativas e retiram água do solo. Assim, embora a cultura não tenha água prontamente disponível nas camadas mais próximas à superfície durante a seca, o maior volume de solo explorado pela mesma contribui para reduzir o déficit hídrico. Como a profundidade explorada pela cultura é diretamente proporcional a AD e considerando as observações de campo em que as raízes de lavouras convencionais exploram uma profundidade de até $0,8 \mathrm{~m}$ (Rena \& Maestri, 2000) a presença de raízes até $1,7 \mathrm{~m}$ nas lavouras estudadas, assegura aproximadamente duas vezes mais água disponível às plantas. O sistema radicular profundo do cafeeiro sob o sistema conservacionista retarda o início e encurta o período total de déficit (Rena \& Maestri, 2000).

Considerando as etapas do ciclo de produção do cafeeiro em que a planta passa por um período de repouso (Matta, 2007), o encurtamento do período de escassez de água assegura sincronismo entre o período de repouso e o período de déficit reduzindo seus efeitos negativos. Essas observações, embora não conclusivas, são respaldadas pelas elevadas produtividades das lavouras manejadas com o sistema conservacionista em questão, com média de 6 anos, de 80 a 100\% superior à média de produtividade de cafeeiros na região do Cerrado que é de 28,6 sacas ha ${ }^{-1}$ (CONAB, 2009). 
Os valores de umidade gravimétrica do período seco (Tabela 5) são elevados mas não estão na faixa de água disponível para as plantas (Figuras 2 e 3). A alta umidade em baixas tensões é característica de Latossolos e está associada aos espaços vazios existentes dentro de seus agregados (Carducci et al., 2011). Em geral, os Cambissolos também são solos com baixa capacidade de água disponível (Ottoni Filho, 2003).

Mesmo abaixo da faixa de água considerada disponível, as plantas permaneceram sem sintomas aparentes de déficit hídrico e continuam produtivas, como observado por Souza \& Paiva (2001) em estudo com citros, em solos com restrições hídricas semelhantes. Esses autores sugerem que as plantas devem absorver água abaixo do PMP e ressaltam que há limitações metodológicas para se avaliar água disponível.

A descrição das raízes no perfil das glebas $\operatorname{LVd}_{3,5}$ e CXbd (Figura 4) evidencia, para o Cambissolo, a presença comum de raízes muito finas e poucas raízes finas. Para o Latossolo foram observadas as mesmas quantidades nas duas classes, com presença de poucas raízes médias.

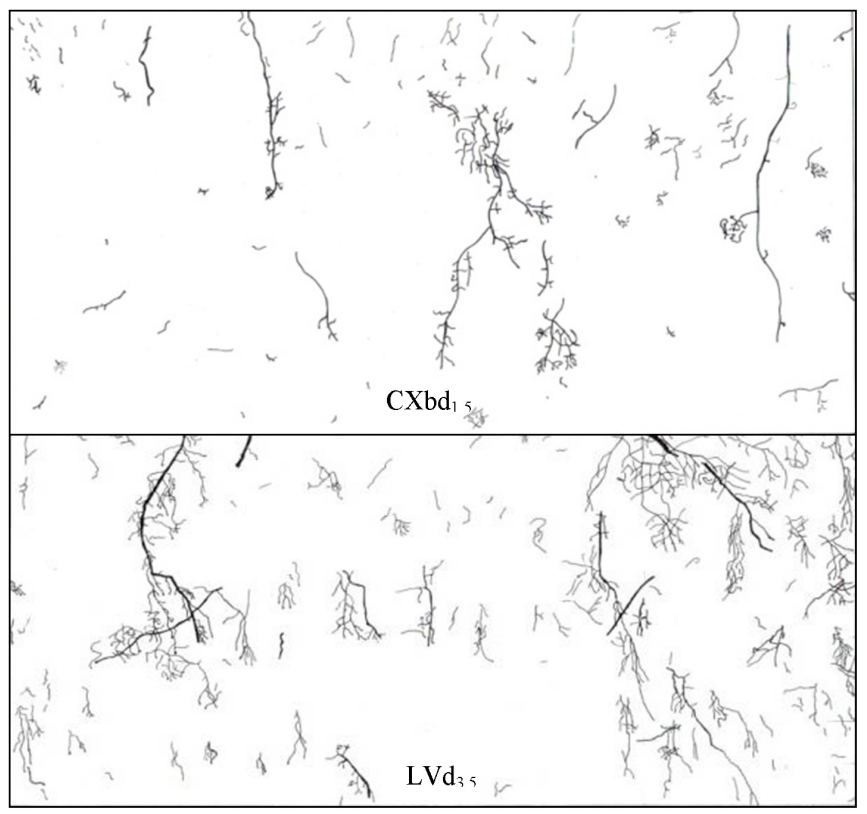

Figura 4. Sistema radicular da lavoura de café em área de Cambissolo (CXbd) e Latossolo (LVd) na camada entre 150 e $170 \mathrm{~cm}$

A presença de raízes nesta camada (1,5 a 1,7 m) (Figura 4) confirma os efeitos positivos do sistema de cultivo adotado, cujas práticas de manejo favorecem o aprofundamento das raízes no perfil. $\mathrm{O}$ uso do gesso agrícola para melhorar as condições químicas do ambiente radicular é uma prática que contribui para o aprofundamento radicular.

No Cambissolo, embora com uma matriz mais densa em relação ao Latossolo, as raízes conseguem penetrar pelo solo e atingir maiores profundidades. Na descrição morfológica do perfil observou-se, macroscopicamente, o saprolito com estrutura de xistosidade do material de origem preservada e uma marcante variação de tonalidade indicadora da variação textural e mineralógica da rocha original (Varajão et al., 2009).

Esta heterogeneidade de material com graus de intemperismo diferentes favorece o aparecimento de veios de solo em profundidade, que são explorados pelas raízes do cafeeiro. As raízes estão presentes também nas linhas de fraqueza que separam os blocos do material. Neste sentido, cabem maiores estudos sobre a importância dessas raízes na nutrição e na absorção de água pelas plantas.

Os 50 tratamentos deste estudo, dados pelas duas posições (linha e entrelinha), cinco profundidades $(0,2 ; 0,4 ; 0,8 ; 1,2$; $1,6 \mathrm{~m})$ e cinco Glebas $\left(\mathrm{CXbd}_{3,5} ; \operatorname{LVd}_{3,5} ; \operatorname{LVd}_{1,5} ; \operatorname{LVd}_{0,5}\right.$ e $\left.\mathrm{CXbd}_{0,5}\right), \log 02 \times 5 \times 5$, foram distribuídos em quatro grupos heterogêneos entre si, pela análise multivariada. A maior concentração de tratamentos foi verificada no grupo 1 reunindose glebas do Latossolo e do Cambissolo latossólico $\left(\mathrm{CXbd}_{3,5}\right)$, confirmando a similaridade desses solos (Tabela 6).

Tabela 6. Agrupamento dos 50 tratamentos pelo método de Tocher, com base nos atributos físicohídricos dos solos (densidade do solo, umidade volumétrica do solo nas datas de amostragem e umidade volumétrica correspondente às tensões de 6, 100 e $1500 \mathrm{kPa}$ )

\begin{tabular}{|c|c|}
\hline Grupo & Tratamentos \\
\hline 1 & $\begin{array}{l}28,33,8,38,35,10,40,3,30,31,34,29,1,36,6,43,5,2 \\
45,11,41,48,13,18,7,27,47,32,23,46,26,15,16,50 \\
25,20 .\end{array}$ \\
\hline 2 & $19,24,14,9,39,49,44$ \\
\hline 3 & $12,17,22,42,37$ \\
\hline 4 & 4 \\
\hline
\end{tabular}

O Método de Tocher reuniu em grupos os tratamentos semelhantes; assim, para visualizar a distribuição das observações dentro de cada grupo mostrando a dissimilaridade entre locais, recorreu-se ao agrupamento com base nas dispersões em relação aos eixos cartesianos; desta forma, os grupos formados são apresentados num gráfico de duas dimensões em que cada área delimitada reúne tratamentos semelhantes. Quanto mais próximos os pontos dentro de um círculo mais similares eles são (Figura 5).

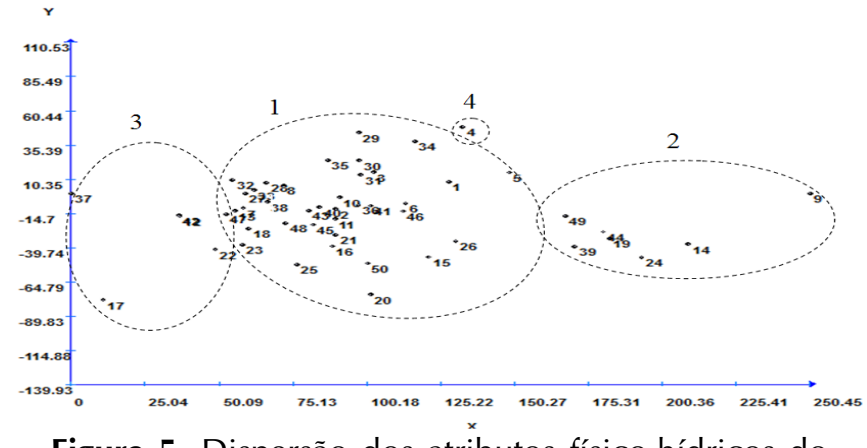

Figura 5. Dispersão dos atributos físico-hídricos do solo nos 50 tratamentos em relação aos eixos representados pelos componentes principais e agrupamento pelo método de Tocher, com base na distância generalizada de Mahalanobis. Elipses delimitam os grupos $(1,2,3$ e 4$)$

Os grupos formados distinguem Latossolos e Cambissolo latossólico $\left(\mathrm{CXbd}_{3,5}\right)$ dos Cambissolos. O Latossolo típico $\left(\operatorname{LVd}_{3,5}\right)$ da baixada da Fazenda Curimba nas camadas da linha e entrelinha abaixo de $0,4 \mathrm{~m}$, foi agrupado separadamente 
em razão da sua baixa densidade e elevada macroporosidade. As camadas de 0,2 e 0,4 m deste local foram agrupadas com os demais Latossolos, certamente por terem passado por intervenções mecânicas semelhantes aos mesmos.

O Cambissolo entrelinha, 0,2 m (grupo 4), foi agrupado separadamente dada à sua alta densidade e elevada proporção de microporos. Nota-se ainda, neste solo, que os pontos referentes a 0,2 e 0,4 m na linha, foram agrupados com os demais Latossolos, destacando-se o efeito do preparo do solo em melhorar os atributos físicos do mesmo. O ponto $0,2 \mathrm{~m}$ da entrelinha apresenta elevada densidade e microporosidade o que o deixou isolado dos demais pontos. A operação de sistematização expondo o horizonte Bi deve ter contribuído para isto.

A densidade do solo (Ds) foi a variável com maior peso na separação dos ambientes enfatizando a diferença deste atributo nas classes de solo estudadas (Tabela 7); a segunda variável em importância foi a umidade volumétrica correspondente a $-6 \mathrm{kPa}$, seguida da umidade a -1500 e $-100 \mathrm{kPa}$. A umidade volumétrica do solo observada em cada coleta apresenta pequeno efeito na distinção dos ambientes por se tratar de uma variável que se altera devido a fatores não relacionados com os atributos do solo; como exemplo, as precipitações pluviais.

Tabela 7. Contribuição relativa das variáveis para diversidade de ambientes - Singh (1981), utilizando-se

Distância Generalizada de Mahalanobis

\begin{tabular}{cc}
\hline Variável $^{*}$ & Valor (\%) \\
Ds & 56,9 \\
$\theta$ & 3,3 \\
$\theta_{6}$ & 19,5 \\
$\theta_{100}$ & 7,6 \\
$\theta_{1500}$ & 12,7 \\
\hline
\end{tabular}

* Variáveis empregadas: Ds densidade do solo, $\theta$ umidade volumétrica do solo nas datas de amostragem; $\theta_{6} \theta_{100} \theta_{1500}$ umidades volumétricas do solo correspondentes às tensões de 6 , 100 e $1500 \mathrm{kPa}$, respectivamente

\section{Conclusões}

1. A disponibilidade hídrica para a cultura do cafeeiro nos solos estudados é dependente da classe de solo e da idade da lavoura.

2. O estudo de componentes principais distinguiu Latossolos de Cambissolos, principalmente pela densidade mais elevada do segundo.

3. A umidade do solo é menor na linha da cultura em relação à entrelinha.

4. A variação sazonal da umidade é significativa até $0,8 \mathrm{~m}$, tendendo a se manter uniforme abaixo desta camada.

\section{Agradecimentos}

À FAPEMIG, ao CNPq e à EMBRAPA Café, pelo apoio financeiro ao projeto e concessão de bolsas aos autores. À EPAMIG, pelo apoio logístico e à Empresa Agropecuária Piumhi (AP) por permitir a instalação do experimento em sua área comercial, além do apoio às atividades de campo.

\section{Literatura Citada}

Böhm, W. Methods of studying root systems. Berlin: SpringerVerlag, 1979. 190p.
Carducci, C. E.; Oliveira, G. C.; Severiano, E. C.; Zeviani, W. M. Modelagem da curva de retenção de água de latossolos utilizando a equação duplo van Genuchten. Revista Brasileira de Ciência do Solo, v.35, p.77-86, 2011.

Castro, M. M. T. Morfología de superficies cultivadas. Em relación com la infiltración, La formación del excedente de agua y La erosión. La Coruña: UDC, 2001. 541p. Tesis Doctoral

CONAB - Companhia Nacional de Abastecimento. < http:// www.conab.gov.br/conabweb/>. 30 Out. 2009.

Cruz, C. D. Programa genes: Biometria. Viçosa: UFV, 2006. $382 p$.

Cruz, C. D.; Regazzi, A. J.; Carneiro, P. C.S . Modelos biométricos aplicados ao melhoramento genético. 3.ed. Viçosa: UFV, 2004. 480p.

EMBRAPA - Empresa Brasileira de Pesquisa Agropecuária. Centro Nacional de Pesquisas de Solos. Manual de métodos de análises de solo, 2.ed., Rio de Janeiro: EMBRAPA: 1997. 212p.

Ferreira, D. F. Sisvar: A computer statistical analysis system. Ciência e Agrotecnologia, v.35, p.1039-1042, 2011.

Fialho, G. S.; Silva, D. P.; Reis, E. F.; Fonseca, A. F. A.; Ferrão, M . A. G. Comportamento de plantas de café arábica submetidas a déficit hídrico durante o desenvolvimento inicial. Idesia, v.28, p.35-39, 2010 .

Franzluebbers, A. J. Water infiltration and soil structure related to organic matter and its stratification with depth. Soil \& Tillage Research, v.66, p.197-205, 2002.

Genuchten, M. T. A closed-form equation for predicting the hydraulic conductivity of unsaturated soils. Soil Science Society of America Journal, v.44, p.892-898, 1980.

IBGE - Instituto Brasileiro de Geografia e Estatística. Manual Técnico de Pedologia do Brasil, Rio de Janeiro: IBGE, 2007. 316p.

Kaiser, D. R.; Reinert, D. J.; Reichert, J. M.; Collares, G. L.; Kunz, M. Intervalo hídrico ótimo no perfil explorado pelas raízes de feijoeiro em um latossolo sob diferentes níveis de compactação. Revista Brasileira de Ciência do Solo, v.33, p.845-855, 2009.

Leite, F. P.; Barros, N. F.; Novais, R. F.; Sans, L. M. A; Fabres, A. S.. Relações hídricas em povoamento de eucalipto com diferentes densidades populacionais. Revista Brasileira de Ciência do Solo, v.23, p.9-16, 1999.

Loyola, J. M. T.; Prevedello, C. L. Modelos analíticos para predição do processo da redistribuição da água no solo. Revista Brasileira de Ciência do Solo, v.27, p.783-787.2003.

Matta, F. M. da; Ronchi, C. P.; Maestri, M.; Barros, R. S.. Ecophysiology of coffee growth and production. Brazilian Journal of Plant Physiology, v.19, p.485-510, 2007.

Menezes, M. D.; Junqueira Júnior, J. A.; Mello, C. R.; Silva, A. M.; Curi, N.; Marques, J. J. Dinâmica hidrológica de duas nascentes, associada ao uso do solo, características pedológicas e atributos físico-hídricos na sub-bacia hidrográfica do Ribeirão Lavrinha - Serra da Mantiqueira (MG). Scientia Forestalis, v.37, p.175-184, 2009.

Oliveira, G. C.; Dias Junior, M. S.; Resck, D. V. S.; Curi, N. Caracterização química e físico-hídrica de um Latossolo Vermelho após vinte anos de manejo e cultivo do solo. Revista Brasileira de Ciência do Solo, v.28, p.327-336, 2004. 
Ottoni-Filho, T. B.. Uma classificação físico-hídrica dos solos. Revista Brasileira de Ciência do Solo, v.27, p.211-222, 2003.

Pereira, A. R. Simplificando o balanço hídrico de ThornthwaiteMather. Bragantia, v.64, p.311-313, 2005.

Petek, M. R.; Patrício, F. R. A. Cultivares resistentes ou tolerantes a fatores bióticos e abióticos desfavoráveis: ponto-chave para a cafeicultura sustentável. O Agronômico, v.59, p.39-40, 2007.

Rena, A. B.; Maestri, M. Relações hídricas no cafeeiro. In: Irrigação \& tecnologia moderna. Brasília: ABID, v.48, p.34-41, 2000.

Sena, M. M.; Frighetto, R. T. S.; Valarini, P. J.; Tokeshi, H.; Poppi, R. J. Discrimination of management effects on soil parameters by using principal component analysis: a multivariate analysis case study. Soil \& Tillage Research, v.67, p.171-181, 2002.

Serafim, M. E.; Oliveira, G. C.; Oliveira, A. S.; Lima, J. M.; Guimarães, P. T. G.; Costa, J. C. Sistema conservacionista e de manejo intensivo do solo no cultivo de cafeeiros na região do Alto São Francisco, MG: Um estudo de caso. Bioscience Journal, v.27, p.964-977, 2011.
Singh, D. The relative importance of characters affecting genetic divergence. Indian Journal of Genetics and Plant Breeding, v.41, p.237-245, 1981.

Souza, L. S.; Paiva, A. Q. de. Variação do potencial total da água em uma topos sequência de solos de tabuleiros, durante dois anos. Pesquisa Agropecuária Brasileira, v.36, p.349-355, 2001.

Souza, L. S.; Souza, L. D.; Paiva, A. Q.; Rodrigues, A. C. V.; Ribeiro, L. S. Distribuição do sistema radicular de citros em uma topos seqüência de solos de tabuleiro costeiro do estado da Bahia. Revista Brasileira de Ciência do Solo, v.32, p.503-513, 2008.

Varajão, C. A. C.; Salgado, A. A. R.; Varajão, A. F. D. C.; Braucher, R.; Colin, F.; Nalini Júnior, H. A. Estudo da evolução da paisagem do quadrilátero ferrífero (Minas Gerais, Brasil) por meio da mensuração das taxas de erosão (10be) e da pedogênese. Revista Brasileira de Ciência do Solo, v.33, p.1409-1425, 2009.

Vieira, S. R.; Angel, M.; Garcia, G.; González, A. P. A. Z.; Siqueira, G. M. Variabilidade espacial e temporal do teor de água do solo sob duas formas de uso. Bragantia, v.69, p.181-190, 2010. 